\title{
Skin Pigmentation
}

National Cancer Institute

\section{Source}

National Cancer Institute. Skin Pigmentation. NCI Thesaurus. Code C35026.

The color of the skin as determined by the amount of melanin present. 